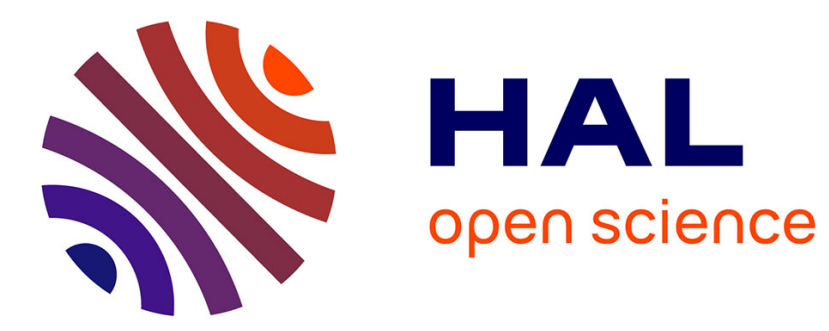

\title{
Period doubling cascade in mercury, a quantitative measurement
}

\author{
A. Libchaber, C. Laroche, S. Fauve
}

\section{To cite this version:}

A. Libchaber, C. Laroche, S. Fauve. Period doubling cascade in mercury, a quantitative measurement. Journal de Physique Lettres, 1982, 43 (7), pp.211-216. 10.1051/jphyslet:01982004307021100 jpa00232033

\section{HAL Id: jpa-00232033 https://hal.science/jpa-00232033}

Submitted on 1 Jan 1982

HAL is a multi-disciplinary open access archive for the deposit and dissemination of scientific research documents, whether they are published or not. The documents may come from teaching and research institutions in France or abroad, or from public or private research centers.
L'archive ouverte pluridisciplinaire HAL, est destinée au dépôt et à la diffusion de documents scientifiques de niveau recherche, publiés ou non, émanant des établissements d'enseignement et de recherche français ou étrangers, des laboratoires publics ou privés. 


\title{
LE JOURNAL DE PHYSIQUE-LETTRES
}

J. Physique - LETTRES 43 (1982) L-211 - L-216

1er AVRIL 1982, PAGE L-211

Classification

Physics Abstracts

$47.20-47.65$

\section{Period doubling cascade in mercury, a quantitative measurement}

\author{
A. Libchaber, C. Laroche and S. Fauve \\ Groupe de Physique des Solides de l'Ecole Normale Supérieure, \\ 24, rue Lhomond, 75231 Paris Cedex 05, France
}

(Reçu le 21 décembre 1981, accepté le 12 février 1982)

\begin{abstract}
Résumé. - Observation de la cascade de doublement de période dans une expérience de RayleighBénard sur le mercure. La cellule expérimentale a un rapport d'aspect $\Gamma=4$ et comporte quatre rouleaux convectifs. Un champ magnétique de $270 \mathrm{G}$ est appliqué le long de l'axe des rouleaux. Le nombre de Feigenbaum mesuré est $\delta=4,4$. Le rapport des sous harmoniques successifs est de l'ordre de $14 \mathrm{~dB}$ pour, les sous harmoniques les plus bas mesurés.

Abstract. - Observation of the period doubling cascade in a Rayleigh-Bénard experiment in mercury. The experimental cell has an aspect ratio $\Gamma=4$ and contains four convective rolls. A DC magnetic field of $270 \mathrm{G}$ is applied along the convective roll axis. The measured Feigenbaum number is $\delta=4.4$. The ratio of the successive subharmonics is of the order of $14 \mathrm{~dB}$ for the lowest measured subharmonics.
\end{abstract}

The period doubling cascade as a route to chaos is now well documented theoretically [1] as well as experimentally [2]. We present here new results on a Rayleigh-Bénard experiment in a cell of liquid mercury with an aspect ratio larger than in previously reported works on helium or water (four convective rolls). The very good signal to noise ratio of the experiment allows a precise determination of the Feigenbaum number and of the power ratio of the successive subharmonics. In this experiment, a DC magnetic field, applied along the convective roll axis, introduces an extra damping of the oscillators which favours the period doubling cascade.

1. An experimental dynamical system with controlled dissipation. - At low Prandtl number, the relevant instability of two-dimensional convective rolls, which leads to time dependent convection and chaos, is the oscillatory instability [3]. It was shown [2] in experiments of convection in liquid helium that for a range of Prandtl numbers and wavenumbers of the convective pattern, one route to chaos is a period doubling cascade, which follows the Feigenbaum scenario [1]. It is customary to compare this type of experiments to a one-dimensional mapping. But this mapping relates to strongly dissipative modes. A more realistic mapping is therefore a two-dimensional one with two parameters, a constraint and a viscosity (area contraction in phase space). The 
simplest quadratic one is the Henon mapping [4] which reduces for infinite contraction to a onedimensional mapping. In a way, we want to find a physical system depending on those two parameters. In a Rayleigh-Bénard experiment, the constraint is the Rayleigh number $R$. At low Prandtl number, the damping of the modes associated with the oscillatory instability depends on the Prandtl number and the wavenumber of the convective pattern [3]. But it is not easy to control such parameters experimentally, and furthermore, they do not affect selectively the oscillatory instability. On the contrary, a horizontal magnetic field, parallel to the convective roll axis, will add a quantitative damping to the oscillatory instability, as we have recently shown [5]. This increased damping of the oscillators will favour the period doubling cascade as a route to chaos [6].

2. Experimental apparatus. - Our experimental system has been described in detail elsewhere $[5,7]$. We use a parallelepipedic cell of aspect ratio $\Gamma=4$ (dimensions $7 \times 7 \times 28 \mathrm{~mm}$ ) with, in the convective state, four rolls parallel to the shorter side wall (see reference five for visualization). The top and bottom boundaries consist of two thick copper plates. The lateral boundaries are made of plexiglass. In the centre of the bottom plate, a small NTC (negative temperature coefficient) thermistor is located on a $2 \mathrm{~mm}$ diameter hole and is adjacent to the convective fluid. The temperature signal, given by the bolometer, is analysed by a $5420 \mathrm{~A} \mathrm{H}$. P. digital analyser. An

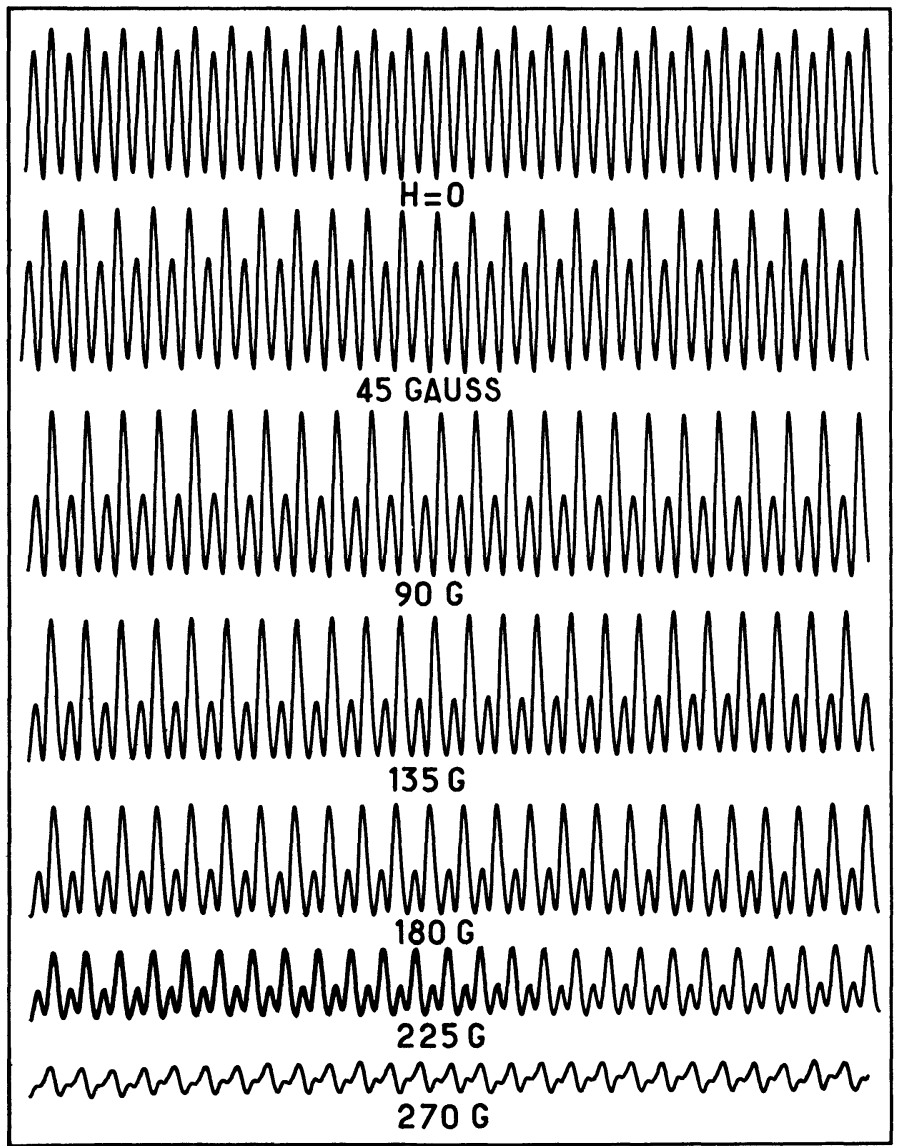

Fig. 1. - Effect of a magnetic field parallel to the roll axis. The Rayleigh number is $R / R_{\mathrm{c}}=2.9$ at zero field. The two oscillators are locked $\left(f_{1} / f_{2}=2\right)$, the amplitude of oscillator $f_{1}$ about $20 \mathrm{~dB}$ larger than the amplitude of oscillator $f_{2}$ for $H=0$. As $H$ increases, the two oscillators tend to the same amplitude and keep their locking ratio 2 . 
electromagnet provides a uniform horizontal magnetic field. The experimental convective cell is placed in a vacuum chamber.

3. Effect of a DC magnetic field, parallel to the roll axis, on the oscillating state - Defining the Rayleigh number for the onset of convection as $R_{\mathrm{c}}$, the first time dependent instability observed is the oscillatory instability, its onset being at $R \simeq 2 R_{\mathrm{c}}$. As previously reported [7], the frequency of the oscillatory mode increases linearly with the Rayleigh number. It allows, by measuring the frequency, a precise determination of each bifurcation point. Increasing slightly the Rayleigh number, a second frequency $f_{2}$ appears in the temperature spectrum which, within a very small range of $R$, locks with $f_{1}$, the ratio being $f_{1}=2 f_{2}$.

We then apply a DC magnetic field parallel to the roll axis up to a field of $270 \mathrm{G}$. We present, in figure 1, the effect of the magnetic field on the direct local temperature recording. Two distinct regimes appear.

For $H>100 \mathrm{G}$, the evolution is the one described in our previous study [5]. The frequency of the oscillatory instability increases and so does the damping of the mode. This will tend at a higher field to a complete inhibition of the oscillatory instability.

But for $H<100 \mathrm{G}$, and the effect is already noticeable around $10 \mathrm{G}$, the relative oscillating strength of the two locked oscillators changes. This sensitivity to a very small field is surprising.

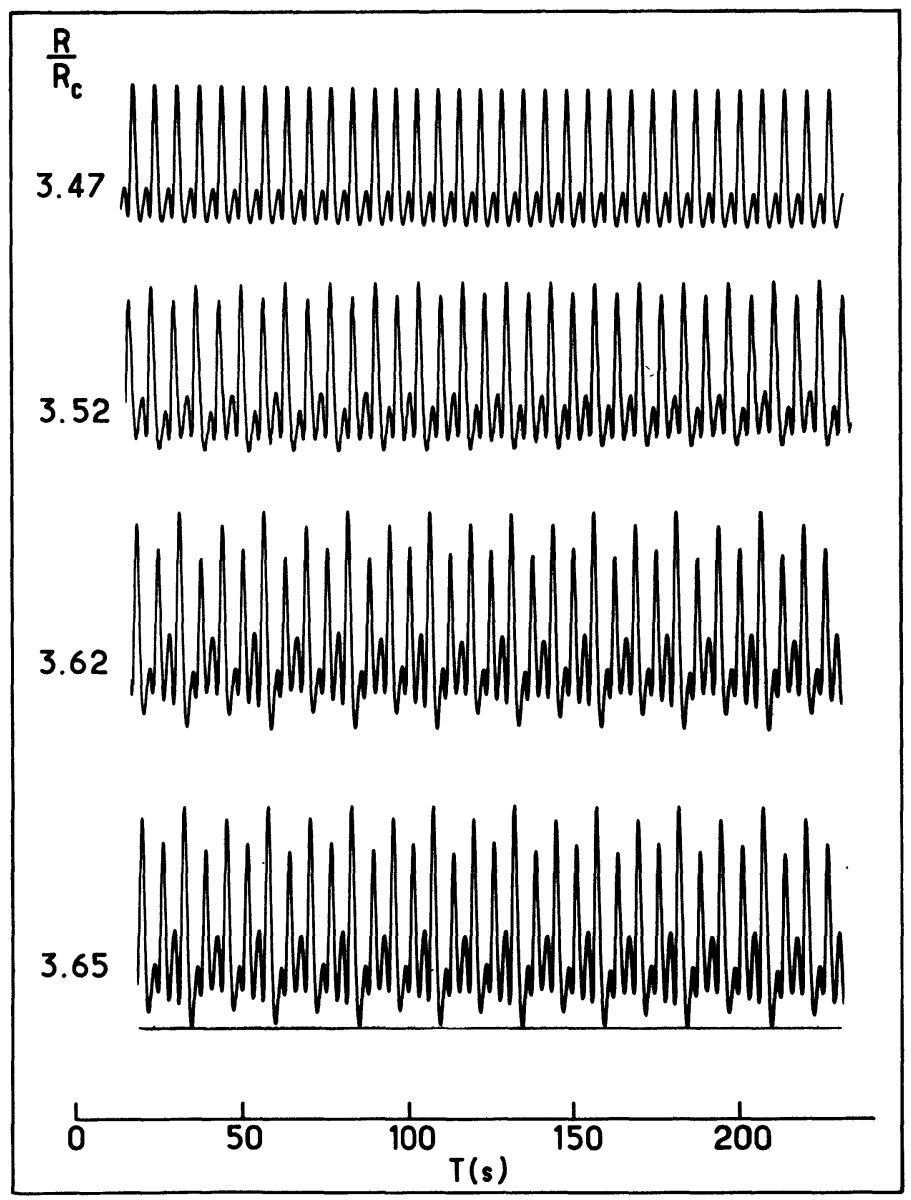

Fig. 2. - Direct time recordings of temperature for various stages of the period doubling cascade showing the onset of $f / 4\left(R / R_{\mathrm{c}}=3.52\right), f / 8\left(R / R_{\mathrm{c}}=3.62\right), f / 16\left(R / R_{\mathrm{c}}=3.65\right)$. 

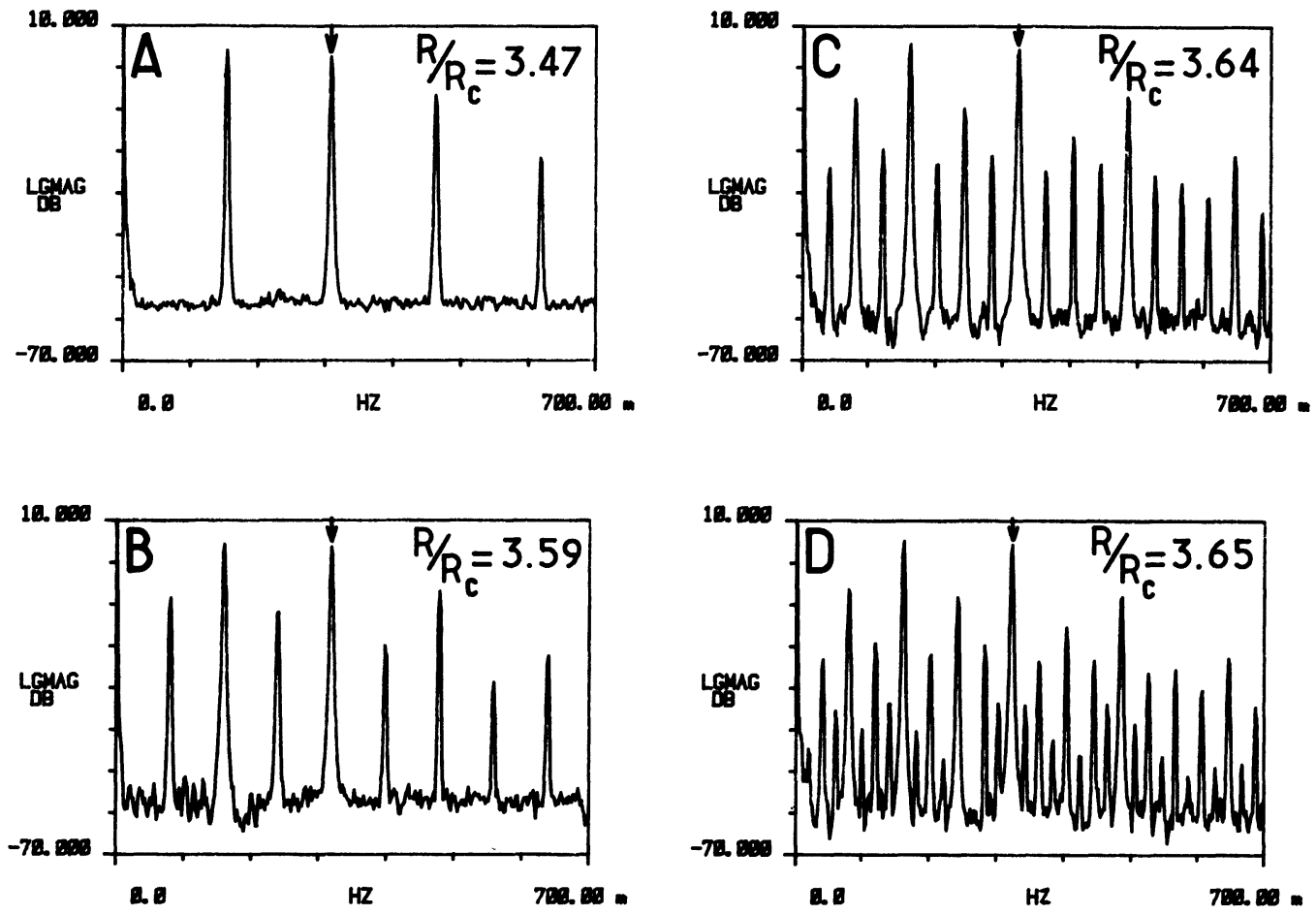

Fig. 3. - The Fourier spectrum. Arrows indicate the peak at the frequency $f_{1}$.

The net result of this phenomenon is that, at $270 \mathrm{G}$, the two modes are highly damped and have about the same oscillating strength, whereas at zero field the mode $f_{1}$ has an amplitude about $20 \mathrm{~dB}$ larger than the mode $f_{2}$.

4. The period doubling cascade. - From now on, we keep a constant magnetic field $H=270 \mathrm{G}$. A typical recording is shown in figure 2 for $R / R_{\mathrm{c}}=3.47$. Let us note that it shows a striking similarity with a recent Cray machine simulation done by Upson et al. [8] on a Rayleigh-Bénard experiment in a small box. The corresponding Fourier spectrum is shown in figure 3A.

As we increase the Rayleigh number, a period doubling cascade develops up to $f / 32$, well resolved as far as the onset values up to $f / 16$.

In table I, we present the various onset values of the cascade of pitchfork bifurcations. In figure 2, the temperature recordings are presented, showing the development of the subharmonics $f / 4$, $f / 8$ and $f / 16$, for $R / R_{\mathrm{c}}=3.52,3.62$ and 3.65. Their respective Fourier spectra are presented in figures $3 \mathrm{~B}, \mathrm{C}, \mathrm{D}$ for values of $R / R_{\mathrm{c}}$ close to the preceding ones.

Table I

$\begin{array}{cc}\begin{array}{c}\text { Onset of } \\ \text { bifurcations }\end{array} & R / R_{\mathrm{c}} \\ \bar{f} / 4 & -\overline{485} \\ & 3.8183 \\ f / 8 & 3.616 \\ f / 16 & 3.6486\end{array}$

$\mu_{4 / 8}=3.5$

$(\sim 11 \mathrm{~dB})$

$\mu_{8 / 16}=5$

(14 dB) 


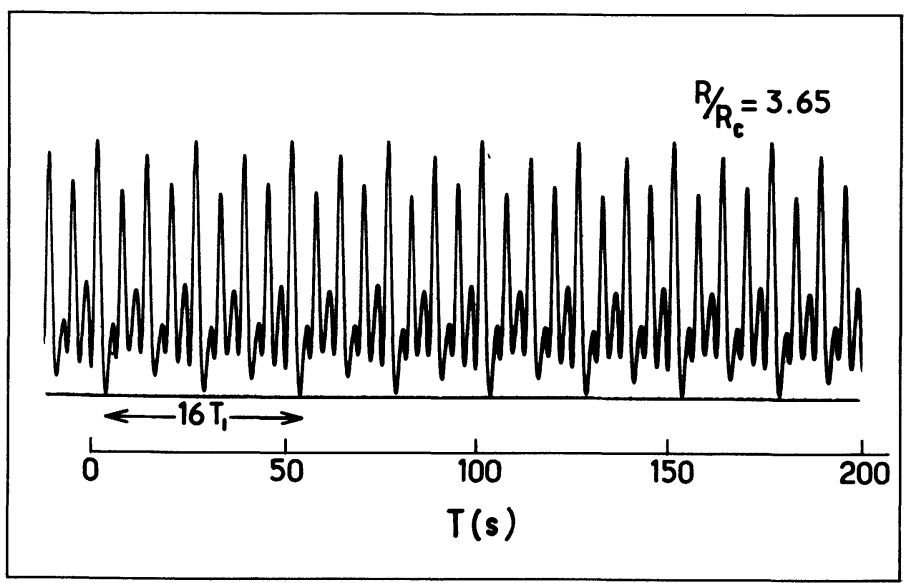

Fig. 4. - Enlargement of the recording showing the development of the cascade.

If we compute the Feigenbaum number $\delta$ for the last three bifurcations, we get

$$
\delta=\frac{R_{8}-R_{4}}{R_{16}-R_{8}}=4.4 \pm 0.1 .
$$

This is to be compared with the theoretical asymptotic value [1] $\delta=4.669$...

We can also compute the ratio of the successive subharmonics amplitude called $\mu$.

This ratio is measured directly on the temperature recordings. We show in figure 4 an enlargement of the temperature signal after the $f / 16$ bifurcation and in figure 5 an enlargement of its Fourier spectrum. The last value of $\mu$ measured is $\mu \sim 5$ to be compared with theoretical values between 4.58 and 6.5 (the first one is given by Nauenberg and Rudnick [9], the second one by Feigenbaum [1]). This measurement of $\mu$ led to some confusion in the past, which can be understood if we look at the Fourier spectrum in figures 3D and 5. It is clear there that the odd harmonics of $f / 16$ have an amplitude which is modulated and depends on the order of the harmonics.

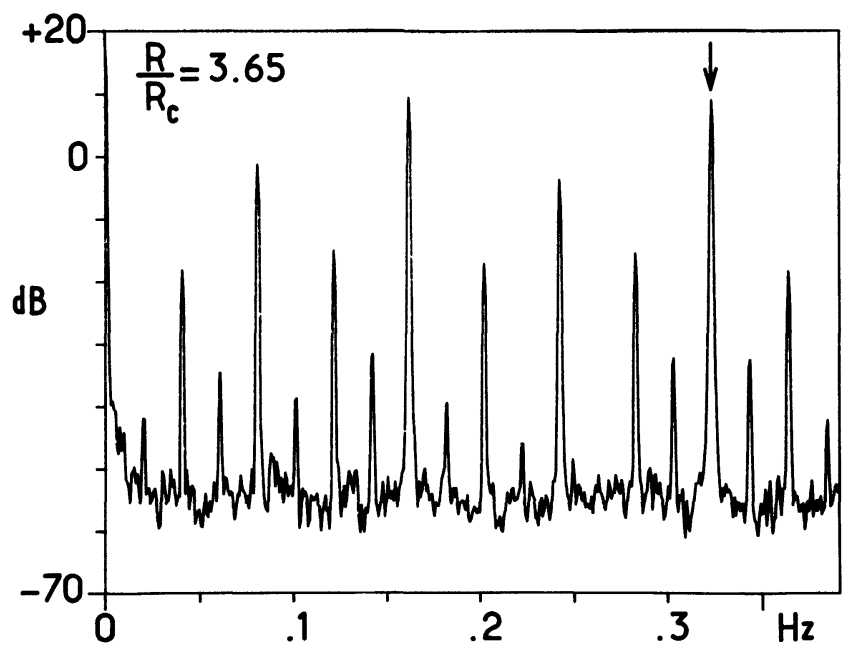

Fig. 5. - Enlargement of the Fourier spectrum corresponding to figure 4. 
It is thus not clear how to calculate the ratio from the Fourier spectrum. The numbers we give in table I are derived from the direct recording.

We have also observed beyond the accumulation point the inverse cascade. Its study and the subtle phenomena of locking windows in the chaotic state will be presented elsewhere.

Let us add some final remarks. Recent computer experiments have shown the role of the breakdown of some spatial symmetries on the onset of chaos [10]. In this respect, the presence of a DC magnetic field plays an important role, such as, for example, introducing an anisotropic effective viscosity. Clearly, for other values of the field and especially at very high fields, other routes to chaos will be found. We must also stress the fact that a very small magnetic field affects the oscillating modes which is somewhat surprising.

\section{References}

[1] Feigenbaum, M. J., Phys. Lett. 75A (1979) 375.

Collet, P. and EckmanN, J. P., Iterated maps on the interval as dynamical systems (Birkhaüser, Boston) 1980.

[2] Maurer, J. and Libchaber, A., J. Physique Lett. 40 (1979) L-419.

LibChaber, A. and Maurer, J., J. Physique Colloq. 41 (1980) C3-51.

Giglio, M., Muzzati, S. and Perini, U., Phys. Rev. Lett. 47 (1981) 243.

Linsay, P. S., Phys. Rev. Lett. 47 (1981) 1349.

[3] Busse, F. H., Rep. Progr. Phys. 41 (1978) 1929.

[4] Henon, M., Commun. Math. Phys. 77 (1976) 50.

[5] Fauve, S., Laroche, C. and Libchaber, A., J. Physique Lett. 42 (1981) L-455.

[6] Arneodo, A., Coullet, P., Tresser, C., Libchaber, A., Maurer, J. and D'Humières, D., About the observation of the uncompleted cascade, preprint.

[7] Fauve, S. and LibChaber, A., Chaos and order in nature, H. Haken Ed., (Springer) 1981.

[8] Upson, C. D., Gresho, P. M., SANI, R. L., Chan, S. T. and Lee, R. L., Lawrence Livermore Lab., Preprint UCRL 85555.

[9] NAUENBERG, M. and RudNick, J., UCSC preprint.

[10]. LIPPS, F. B., J. Fluid Mech. 75 (1976) 113.

Mc Laughlin, F. B. and Orszag, S. A., preprint. 